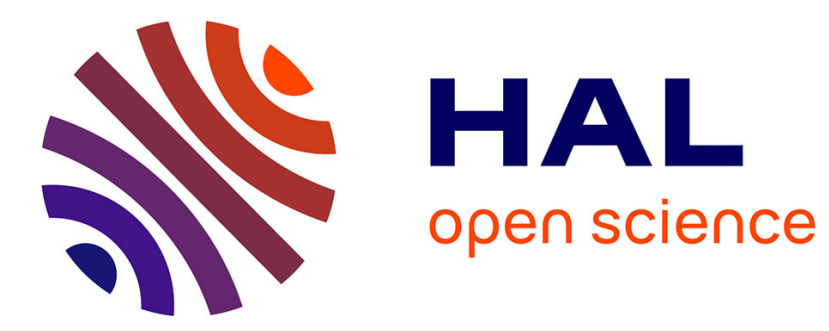

\title{
OPTIMIZATION MODELS FOR THE DYNAMIC FACILITY LOCATION AND ALLOCATION PROBLEM
}

Riccardo Manzini, Elisa Gebennini

\section{- To cite this version:}

Riccardo Manzini, Elisa Gebennini. OPTIMIZATION MODELS FOR THE DYNAMIC FACILITY LOCATION AND ALLOCATION PROBLEM. International Journal of Production Research, 2008, 46 (08), pp.2061-2086. 10.1080/00207540600847418 . hal-00512932

\section{HAL Id: hal-00512932 \\ https://hal.science/hal-00512932}

Submitted on 1 Sep 2010

HAL is a multi-disciplinary open access archive for the deposit and dissemination of scientific research documents, whether they are published or not. The documents may come from teaching and research institutions in France or abroad, or from public or private research centers.
L'archive ouverte pluridisciplinaire HAL, est destinée au dépôt et à la diffusion de documents scientifiques de niveau recherche, publiés ou non, émanant des établissements d'enseignement et de recherche français ou étrangers, des laboratoires publics ou privés. 


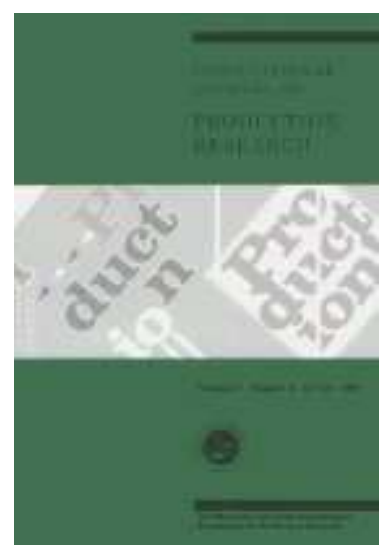

\section{OPTIMIZATION MODELS FOR THE DYNAMIC FACILITY LOCATION AND ALLOCATION PROBLEM}

\begin{tabular}{|c|c|}
\hline Journal: & International Journal of Production Research \\
\hline Manuscript ID: & TPRS-2006-IJPR-0199 \\
\hline Manuscript Type: & Original Manuscript \\
\hline $\begin{array}{r}\text { Date Submitted by the } \\
\text { Author: }\end{array}$ & 10-Mar-2006 \\
\hline Complete List of Authors: & $\begin{array}{l}\text { Manzini, Riccardo; University of Bologna, Department of Industrial } \\
\text { Mechanical Plants (DIEM) } \\
\text { Gebennini, Elisa; University of Modena and Reggio Emilia, } \\
\text { Department of Engineering Sciences and Methods }\end{array}$ \\
\hline Keywords: & $\begin{array}{l}\text { SUPPLY CHAIN DYNAMICS, SUPPLY CHAIN MANAGEMENT, FACILITY } \\
\text { PLANNING, FACILITY LOCATION, LOGISTICS }\end{array}$ \\
\hline Keywords (user): & LOCATION ALLOCATION PROBLEM, LOGISTIC NETWORK DESIGN \\
\hline
\end{tabular}

\section{今 scholarONE" \\ Manuscript Central}




\title{
OPTIMIZATION MODELS FOR THE DYNAMIC FACILITY LOCATION AND ALLOCATION PROBLEM
}

\author{
Riccardo Manzini $(\ddagger)$, Elisa Gebennini $(\dagger)$ \\ Department of Industrial Mechanical Plants, University of Bologna, \\ Viale Risorgimento 2, 40136 Bologna - Italy \\ $(\dagger)$ Department of Engineering Sciences and Methods, \\ University of Modena and Reggio Emilia - Italy \\ (\$) Corresponding author: tel.: 051 2093406; fax: 0512093411 \\ Email: riccardo.manzini@mail.ing.unibo.it
}

\begin{abstract}
The design of logistic distribution systems is one of the most critical and strategic issues in industrial facility management. The aim of this study is to develop and apply innovative mixed integer programming optimization models to design and manage dynamic (i.e. multi-period) multistage and multi-commodity location-allocation problems (LAP).

LAP belong to the NP-hard complexity class of decision problems, and the generic occurrence requires simultaneous determination of the number of logistic facilities (e.g. production plants, warehousing systems, distribution centers), their locations, and assignment of customer demand to them.

The proposed models use a mixed integer linear programming solver to find solutions in complex industrial applications even when several entities are involved (production plants, distribution centers, customers, etc.). Lastly, an application of the proposed models to a significant case study is presented and discussed.
\end{abstract}

Keywords: location allocation problem (LAP), multi-period facility location, logistic network design, supply chain management (SCM). 


\section{$1 \quad$ Introduction}

A very large set of studies regarding facility management in several engineering areas can be found in the literature e.g. transportation, manufacturing, logistics, computer research, etc. These studies specifically reveal that facility location (FL) decisions are one of the most critical elements in strategic logistics planning and in control of logistic distribution networks. The major logistical components of a generic distribution systems are: a number of manufacturing plants; either zero, one, or more than one distribution echelon composed of so-called distribution centers (DCs); customers, i.e. points of demand; raw material and component suppliers; and lastly, the transportation network. Consequently, logistics managers are frequently asked the following questions: in which plant and in which country is it most profitable to manufacture a specific product? Which transportation modes best serve the customer points of demand (located worldwide)? Which is the optimal location and storage capacity of a DC? In response, this study aims to develop and apply a set of models capable of supporting these management decisions.

In particular, the purpose of this manuscript is to design, test, and compare innovative models for the dynamic (i.e. multi-period) location allocation problem (LAP). The paper is organized as follows: Section 2 discusses the main FL and LAP contributions to be found in the literature. Sections 3, 4, 5, and 6 present four different innovative mixed integer linear models applied to the dynamic LAP of a generic company that operates worldwide. Then Section 7 describes the application of the proposed models to a significant case study, and lastly, the final section presents conclusions and suggestions for further research.

\section{Review of the literature}

Various studies on logistical FL are to be found in the literature. They examine the main strategies companies use to compete in global markets (Chakravarty 1999): 
The generic FL problem in logistic systems can be defined as the taking of simultaneous decisions regarding design, management, and control of a generic distribution network (Manzini et al. 2005 and 2006):

1. location of new supply facilities in a given set of demand points. The demand points correspond to existing customer locations;

2. demand flows to be allocated to available or new suppliers;

3. configuration of a transportation network i.e. design of paths from suppliers to customers, management of routes and vehicles in order to supply demand needs simultaneously.

The problem of finding the best of many possible locations can be solved by several qualitative and efficiency site selection techniques e.g. ranking procedures and economic models (Byunghak and Cheol-Han 2003, Manzini et al. 2004). These techniques are still largely influenced by subjective and personal opinions (Love et al. 1988, Sule 2001). Consequently, the problems of location analysis are generally and traditionally categorized into one of the following broad classes of quantitative and quite effective methods (Francis et al. 1983, Love et al. 1988, Francis et al. 1992, Sule 2001, Yurimoto and Katayama 2002, Klose and Drexl 2005, Manzini et al. 2006):

- Single facility minimum location problems: they support the choice of the optimal location of a single facility designed to serve a pool of existing customers. Young and Hwan (2003) present an example.

- Multiple facility location problems $(M F L P)$. This class of problems extends the analysis to encompass multiple facilities, which are capable of serving the customers in the same or in different ways, the aim being to find the optimum site for each facility. Examples of classes 
of MFLPs discussed in the literature (Manzini et al. 2006) are the following: p-Median problem $(p-M P)$, p-Centre problem $(p-C P)$, uncapacitated facility location problem (UFLP), capacitated facility location problem (CFLP), quadratic assignment problem (QAP), and plant layout problem (Sule et al. 2001, Catena et al. 2003, Ferrari et al. 2003).

- Facility location allocation problem (LAP). In an operating context where there is more than one new facility to be located, part of the location problem is often composed of determining the flows between the new facilities and the existing facilities (i.e. demand points). By this definition the LAP is an MFLP with unknown allocation of demand to the available facilities (the so-called allocation sub problem). The number of new facilities may also be part of the problem, and the cost of adding a new facility (i.e. high profit margin strategy) could be balanced by the transportation cost saved and process improvement policies. In general, the number of facilities may be known or unknown. The problem is to determine the optimal location for each of the $m$ new facilities and the optimal allocation of existing facility requirements to the new facilities so that all requirements are satisfied, that is, when the set of existing facility locations and their requirements are known. The literature presents several models and approaches to treating location of facilities and allocation of demand points simultaneously. In particular, Love et al. (1988) discuss the following site-selection LAP models: set-covering (and set-partitioning models); single-stage, single-commodity distribution model; and two-stage, multicommodity distribution model which deals with the design for supply chains composed of production plants, DCs, and customers.

- Network location problem (NLP). This class of problems belongs to the previously described facility LAP. However, instead of somehow approximating the transport network by using a planar multi-facility location based approach (i.e. distance, time, and cost between new and existing facilities), the model is applied to the network directly and so involves the additional onerous effort of constructing and configuring the network itself. In 
other words, one of the main aims of this problem is to select specific paths from different nodes in the available network.

Sule (2001) presents and discusses advanced extension classes of the LAP and NLP including the tours development problem (Jalisi and Cheddad 2000), the vehicle routing problem (e.g. assignment procedures for the travelling salesman problem and the truck routing problem), and the multi-period dynamic facility location problem. Ambrosino and Scutellà (2005) present two different kinds of mathematical formulations for the integrated distribution network design problem. These contemplate several types of decision such as locations, allocation, routing and inventory decisions. However, despite this recent contribution (Ambrosino and Scutellà 2005), the models presented below in this paper consider various aspects of practical importance such as production and delivery lead times, penalty cost for unfulfilled demand, and response times different customers are willing to tolerate.

The subject of this manuscript is the multi-period LAP problem and not the NLP. Consequently, in this paper the term network is synonymous with distribution system (i.e. supply chain): construction and configuration of the network are intentionally omitted.

Previous discussion of FL problems show that they can be classified as supply chain management (SCM) problems as demonstrated by the theoretical framework introduced by Chen and Paularaj (2004). In particular, they discuss the so-called supply network coordination that focuses on the mathematical modeling approach to SCM.

So-called "dynamic location models" consider a multi-period operating context where the demand varies between different time periods. This configuration of the problem aims to answer three important questions. Firstly, where i.e. the best places to locate the available facilities. Secondly, what size i.e. which is the best capacity to assign to the generic logistic facility. Thirdly, when i.e. with regard to a specific location, which periods of time demand a certain amount of production capacity (Jacobsen, 1990). Furthermore, Wesolowsky (1973), Wesolowsky and Truscott (1975), and Sweeney and Tatham (1976) deal with the multi-period location-allocation problem: the 
starting point is the static LAP, after which dynamic programming is applied to introduce dynamic considerations in order to find the optimal multi-period solution. Van Roy and Erlenkotter (1982) propose a dual approach to solving the dynamic uncapacitated facility location problem (DUFLP), whose aim is to minimize total discounted costs when demand at various customer locations changes between time-periods. Canel et al. (2001) introduce an algorithm for the capacitated, multicommodity, multi period facility location problem. Gen and Syarif (2005) recently proposed a spanning tree-based genetic algorithm for multi-time period production/distribution planning. All these studies propose algorithms to solve the dynamic location problems but neither focus on nor apply the models to real logistic networks, whose complexity easily compromises the efficacy of the proposed solving approaches.

Several manuscripts discuss facility location in conditions of uncertainty (ReVelle 1989, Owen and Daskin 1998, Current et al. 1998, Chiyoshi et al. 2003, Lin and Chen 2003, Lodree et al. 2004, Blackhurst et al. 2004). Daskin (2003) in particular classifies these approaches into two main categories:

- stochastic programming: discrete scenarios are used to describe the uncertain parameters, each scenario having a given probability of occurrence;

- robust optimization: the typical objective is to minimize the worst-case cost.

Whereas robust facility location models deal with uncertainty of the available input data, reliability models treat uncertainty in the solution itself e.g. stochastic availability of logistic facilities (Lawrence and Daskin 2005).

Furthermore, regarding the integration of tactical decision in the distribution network design problem, Shen et al. (2003) propose a joint location-inventory model that incorporates demand uncertainty and focuses on minimizing the facility location costs, the inventory management costs, and the distribution costs. More recently Miranda and Garrido (2004) have developed a model to find the optimal configuration of a distribution network which also considers the inventory control 
decisions and the risk pooling effect. Nevertheless, both these models are non-linear and therefore very difficult to solve without using heuristic approaches.

The aim of this study is to present and apply an innovative set of linear-integer programming models to the dynamic LAP in order to incorporate tactical decisions regarding inventory control, production rates, and service levels. These models significantly extend a previous study carried out by Manzini et al. (2006) which focused on the design of a single period multi-stage distribution system. As a result, the models proposed by Manzini et al. (2006) deal with the strategic activity of planning and design a distribution system, while the new study presented here introduces original models capable of supporting both strategic and tactical management decisions.

In particular, the solutions obtained identify the facilities to be kept open, the allocation of regional demands to these facilities, the optimal product flow along the supply chain in any time period $t$, the optimal production level in $t$, and finally, the optimal inventory level of each available logistic facility. The proposed models aim to minimize the total network costs and, at the same time, to maximize the customer service level by respecting delivery due dates and minimizing stock-outs.

The importance of the proposed models essentially lies in the ability of a linear programming solver to solve optimally large complex instances of the dynamic LAP within acceptable computational times. Authors of recent papers (Amiri 2006 and Shen 2005) address the distribution network design problem by developing heuristic solutions procedure to reduce the prohibitive CPU time required to find the optimal solution using commercial optimization software. This requirement underlines the importance of formulating the problem as a mixed integer model that can also be optimally solved for real instances involving a large number of constraints and variables. The solvability of the dynamic LAP is demonstrated by applying the proposed models to a significant case study which involves several entities (e.g. production facilities, warehouses, points of demands) and products in a complex distribution system. 


\section{Single-commodity, multi-period, 2-stage model (SCMP2S)}

This section presents an innovative single-commodity, multi-period, two-stage facility location and allocation model. This model is suitable for a logistic network composed of two different stages (Figure 1) and which involves three types of nodes (i.e. levels): a production plant or a central distribution center (CDC), a pool of regional distribution centers (RDCs), and finally, a set of customers (i.e. points of demand).

[Insert Figure 1 about here]

The proposed model is able to simultaneously identify the following set of variables:

- number and locations of regional distribution centers (RDCs) to be kept open during a planning horizon of time $T$ (e.g. a year);

- the optimal product flows along the logistic network in any time period $t$ belonging to $T$;

- the optimal production level in any time period $t$;

- the optimal inventory level in any available DC in any $t$.

The previously defined variables are determined by minimizing the total network logistical costs and delays. Because the logistic network is composed of two stages, there are two different kinds of product flows to consider:

- from the production plant to the RDCs through the CDC. The CDC acts as a transit point for delivering products that must go to both RDCs and final customers;

- from RCDs to customers.

The planning horizon time $T$ is divided into shorter periods, and the proposed multi-period model provides the trend of each variable through time. This means that several lead times need to be identified along the supply chain so that efficient production, inventory, and delivery activities can 
be planned. The different kinds of lead time managed by the dynamic model are as follows (see Figure 1):

- production lead time from production level to CDC;

- delivery lead times from CDC to RDCs;

- delivery lead times from RDCs to customers.

Prior to mathematical formulation of the SCMP2S, consideration needs to be given to the following assumptions:

- the capacity of the warehousing system is neglected: this choice is consistent with the objective of minimizing a logistic function which measures the number and location of the facilities adopted;

- the inventory holding unit cost is constant and assumes the same value for all DCs;

- the cumulative available productive capacity during the planning period $T$ meets the total amount of demand. Nevertheless, the productive capacity in any time period $t$ could be incapable of satisfying the customer demand. As a result, the system generally needs to produce products in advance and to store quantities of product in inventory systems located at various points in the distribution logistic network. In fact demand is not constant through the different periods $t$, especially in cases with considerable seasonal effects.

In order to avoid computational complexity in cases of instances involving a large problem, the models proposed in this paper do not incorporate stochastic demands. Nevertheless, the uncertainty can be simulated by processing multi-scenario analyses (i.e. what-if analysis).

The linear model is:

$$
\begin{aligned}
& \operatorname{Min} \sum_{k=1}^{K}\left(c_{k}^{\prime} d_{k}^{\prime} \sum_{t=1}^{T} x_{k t}^{\prime}\right)+\sum_{k=1}^{K} \sum_{l=1}^{L}\left[c_{k l} d_{k l} \sum_{t=1}^{T}\left(x_{k l t}+x_{k l t}^{\text {delay }}\right)\right]+\sum_{k=1}^{K} \sum_{t=1}^{T} c^{p} x_{k t}^{\prime}+\sum_{k=1}^{K} \sum_{t=1}^{T} c^{s} I_{k t}+ \\
& +\sum_{k=1}^{K} f_{k} z_{k}+\sum_{k=1}^{K} \sum_{t=1}^{T} v_{k} x_{k t}^{\prime}+W \cdot \sum_{k=1}^{K} \sum_{l=1}^{L} \sum_{t=1}^{T} S_{k l t}
\end{aligned}
$$


subject to

$P_{t} \leq C_{t}^{P} \quad \forall t$

$P_{t-l t^{\text {prod }}}=\sum_{k=1}^{K} x_{k t}^{\prime}$

$\forall t$

$I_{k, t-1}-I_{k, t}+x_{k, t-t_{k}^{\text {deliv }}}^{\prime}=\sum_{l=1}^{L} x_{k l t}+\sum_{l=1}^{L} S_{k l, t-1} \quad \forall k, t$

$I_{k t} \leq D_{t o t} \cdot z_{k}$

$\forall k, t$

$x_{k l t}+S_{k l t}=D_{l,\left(t+t_{k l}^{e v}\right)} y_{k l,\left(t+t_{k l}^{e v}\right)}$

$\forall k, l, t$

$x_{k l t}^{\text {delay }}=S_{k l, t-1}$

$\forall k, l, t$

$\sum_{l=1}^{L} x_{k l t}^{\text {delay }} \leq D_{\text {tot }} \cdot z_{k}$

$\forall k, t$

$\sum_{l=1}^{L} y_{k l t} \leq p \cdot z_{k}$

$\forall k, t$

$\sum_{k=1}^{K} y_{k l t}=1 \cdot D_{k l}^{N N u l l}$

$\forall l, t$

$t_{k l}^{e v} y_{k l t} \leq T_{l}$

$\forall k, l, t$

$I_{k 0}=I_{k}^{\text {begin }}$

$\forall k$

$S_{k l 0}=S_{k l}^{\text {begin }}$

$\forall k, l$

$S_{k l T}=0$

$\forall k, l$

$x_{k l t} \geq 0$

$\forall k, l, t$

$x_{\text {klt }}^{\text {delay }} \geq 0$

$\forall k, l, t$

$S_{k l t} \geq 0$

$\forall k, l, t$

$I_{k t} \geq 0$

$\forall k, t$

$z_{k}, y_{k l t} \in\{0,1\}$

$\forall k, l, t$

where:

$k=1, \ldots, K \quad$ RDC belonging to the logistic network second level;

$l=1, \ldots, L \quad$ demand point belonging to the third level of the network;

$t=1, \ldots, T \quad$ unit period of time along the planning horizon $T$;

$x_{k t}^{\prime} \quad$ product quantity from the CDC to the RDC $k$ in $t$;

$x_{k l t} \quad$ on time delivery quantity i.e. product quantity from the RDC $k$ to the point of demand $l$ in $t$;

$S_{k l t} \quad$ product quantity not delivered from the RDC $k$ to the point of demand $l$ in $t$. The admissible period of delay is one unit of time: consequently, this quantity must be delivered in the period $t+1$; 
delayed product quantity delivered late from the RDC $k$ to the point of demand $l$ in $t$. The value of this variable corresponds to $S_{k l, t-1}$; storage quantity in the RDC $k$ at the end of the period $t$; production quantity in time period $t$. It is available after the lead time $l t^{\text {prod }}$; 1 if the RDC $k$ supplies the point of demand $l$ in $t$; 0 otherwise; 1 if the RDC $k$ belongs to the distribution network; 0 otherwise; unit cost of transportation from the CDC to the RDC $k$; distance from the CDC to the RDC $k$; unit cost of transportation from the RDC $k$ to the point of demand $l$; distance from the RDC $k$ to the point of demand $l$; additional unit cost of stock-out; production unit cost; unit inventory cost which refers to $t$. If $t$ is one week, the cost is the weekly unit storage cost;

$f_{k} \quad$ fixed operative cost of the RCD $k$;

$v_{k}$ variable unit (i.e. for each unit of product) cost based on the product quantity which flows through the RDC $k$;

$D_{l t} \quad$ demand from the point of demand $l$ in the time period $t$;

$S_{k l}^{\text {begin }}$ starting stock-out at the beginning $(t=0)$ of the horizon of time $T$;

$I_{k}^{\text {begin }}$ starting storage quantity in RDC $k$; maximum number of points of demand supplied by a generic RDC in any time period;

$D_{t o t}=\sum_{l=1}^{L} \sum_{t=1}^{T} D_{l t} \quad$ total amount of customer demand during the planning horizon $T$; $C_{t}^{P} \quad$ productive capacity available in $t$;

$D_{l t}^{\text {NNull }} \quad 1$ if demand from the customer $l$ in $t$ is not null; 0 otherwise;

$T_{l} \quad$ delivery time required by the point of demand $l$;

$l t^{\text {prod }} \quad$ production lead time;

$t_{k}^{\text {deliv }} \quad$ delivery lead time from the CDC to the generic RDC $k$;

$t_{k l}^{e v} \quad$ delivery lead time from the RDC $k$ to the point of demand $l$.

The objective function is composed of various contributions (seven addends):

1. total cost of transportation from the first level (CDC) to second level (RDCs);

2. total cost of transportation from the second level (RDCs) to third level (points of demand); 
3. total production cost;

4. total storage cost;

5. total amount of fixed costs for the available RDCs;

6. total amount of variable costs for the available RDCs;

7. total amount of extra stock-out cost. The parameter $W$ is a large number so that solutions capable of respecting the customer delivery due dates can be proposed.

The more significant constraints are expounded as follows:

- (1.2) states that the starting time of production of the CDC output quantity in $t$ is ;

- (1.3) guarantees the conservation of logistic flows to each facility in each period of time $t$;

- (1.5) states that the product quantity from the RDC $k$ to the point of demand $l$ is delivered according to a lead time $t_{k l}^{e v}$ in order to satisfy the demand of period $t+t_{k l}^{e v}$. Stock-outs are backlogged and supplied in the following period;

- (1.9) guarantees the individual sourcing requirement: if the demand of node $l$ in $t$ is not null $\left(D_{l t}^{N N u l l}=1\right)$, only one RDC must serve the point of demand $l$; otherwise $\left(D_{l t}^{N \text { Null }}=0\right)$ the point of demand $l$ is not assigned to any facilities;

- (1.10) ensures that a demand node is only assigned to an RDC if it is possible to carry out the order by the customer delivery due date.

\section{Multi-commodity, multi-period, 2-stage model (MCMP2S)}

The main assumption of the previous model is that the production plant only distributes one type of product to the pool of customers. In reality most industrial companies produce and distribute a wide mix of different products: consequently the logistic network has to manage more than one product family. 
The problem can be formulated as the following mixed integer linear model:

$$
\begin{aligned}
& \operatorname{Min} \sum_{k=1}^{K} \sum_{f=1}^{F}\left(c_{f k}^{\prime} d_{k}^{\prime} \sum_{t=1}^{T} x_{f k t}^{\prime}\right)+\sum_{k=1}^{K} \sum_{l=1}^{L} \sum_{f=1}^{F}\left(c_{f k l} d_{k l} \sum_{t=1}^{T}\left(x_{f k l t}+x_{f k l t}^{\text {delay }}\right)\right)+\sum_{k=1}^{K} \sum_{t=1}^{T} \sum_{f=1}^{F} c_{f}^{p} x_{f k t}^{\prime}+ \\
& +\sum_{k=1}^{K} \sum_{t=1}^{T} \sum_{f=1}^{F} c_{f}^{s} I_{f k t}+\sum_{k=1}^{K} f_{k} z_{k}+\sum_{k=1}^{K} \sum_{t=1}^{T} \sum_{f=1}^{F} v_{k} x_{f k t}^{\prime}+W \cdot \sum_{k=1}^{K} \sum_{l=1}^{L} \sum_{t=1}^{T} \sum_{f=1}^{F} S_{f k l t}
\end{aligned}
$$

subject to

$\sum_{f=1}^{F} P_{f t} \leq C_{t}^{P}$

$\forall t$

$P_{f, t-l t^{p r o d}}=\sum_{k=1}^{K} x_{f k t}^{\prime}$

$\forall f, t$

$I_{f k, t-1}-I_{f k, t}+x_{f k, t-t_{k}^{d e l i v}}^{\prime}=\sum_{l=1}^{L} x_{f k l t}+\sum_{l=1}^{L} S_{f k l, t-1} \quad \forall f, k, t$

$I_{f k t} \leq D_{f}^{t o t} \cdot z_{k}$

$\forall k, t$

$x_{f k l t}+S_{f k l t}=D_{f l,\left(t+t_{k l l}^{e v}\right)} y_{f k l,\left(t+t_{k l}^{e v}\right)}$

$\forall k, l, t$

$x_{f k l t}^{\text {delay }}=S_{f k l, t-1}$

$\forall k, l, t$

$\sum_{l=1}^{L} x_{f k l t}^{\text {delay }} \leq D_{f}^{\text {tot }} \cdot z_{k}$

$\forall f, k, t$

$\sum_{l=1}^{L} \sum_{f=1}^{F} y_{f k l t} \leq p \cdot z_{k}$

$\forall k, t$

$\sum_{k=1}^{K} y_{f k l t}=1 \cdot D_{f k l}^{N N u l l}$

$\forall f, l, t$

$t_{k l}^{e v} y_{f k l t} \leq T_{l}$

$\forall f, k, l, t$

$I_{f k 0}=I_{f k}^{\text {begin }}$

$\forall f, k$

$S_{f k l 0}=S_{f k l}^{\text {begin }}$

$\forall f, k, l$

$S_{f k l T}=0$

$\forall f, k, l$

$x_{f k l t} \geq 0$

$\forall f, k, l, t$

$x_{\text {fklt }}^{\text {delay }} \geq 0$

$\forall f, k, l, t$

$S_{f k l t} \geq 0$

$\forall f, k, l, t$

$I_{f k t} \geq 0$

$\forall f, k, t$

$z_{k}, y_{f k l t} \in\{0,1\}$

$\forall f, k, l, t$ 
where:

$$
\begin{aligned}
& f=1, \ldots, F \quad \text { product family; } \\
& x_{f k t}^{\prime} \quad \text { quantity of product family } f \text { from the CDC to the RDC } k \text { in } t \text {; } \\
& x_{f k l t} \quad \text { on time delivery quantity of product family } f \text { from the RDC } k \text { to the point of } \\
& \text { demand } l \text { in } t \text {; } \\
& S_{f k l t} \quad \text { quantity of product family } f \text { not delivered from the RDC } k \text { to the point of } \\
& \text { demand } l \text { in } t \text {. This quantity has to be delivered in the period } t+1 \text {; } \\
& x_{f k l t}^{\text {delay }} \quad \text { quantity of product family } f \text { delivered late from the RDC } k \text { to the point of } \\
& \text { demand } l \text { in } t \text {. The value of this variable corresponds to } S_{k l, t-1} \text {; } \\
& I_{f k t} \quad \text { storage quantity of product family } f \text { in the RDC } k \text { at the end of period } t \text {; } \\
& y_{f k l t} \quad 1 \text { if the RDC } k \text { supplies the point of demand } l \text { with product family } f \text { in } t ; 0 \\
& \text { otherwise; } \\
& c_{f k}^{\prime} \quad \text { unit cost of transportation for product family } f \text { from the CDC to the RDC } k \text {; } \\
& c_{k l} \quad \text { unit cost of transportation for product family } f \text { from the RDC } k \text { to the point of } \\
& \text { demand } l \text {; } \\
& c_{f}^{p} \quad \text { unit cost of production for product family } f \\
& c_{f}^{s} \quad \text { inventory storage cost of product family } f \text {. This cost refers to } t \text { (e.g. one } \\
& \text { week); } \\
& D_{f l t} \quad \text { demand for product family } f \text { from the point of demand } l \text { in the period of time } \\
& t \\
& S_{f k l}^{\text {begin }} \quad \text { starting stock-out of the product family } f(t=0) \text {; } \\
& I_{f k}^{\text {begin }} \quad \text { starting storage quantity in the RDC } k \text { of the product family } f(t=0) \text {; } \\
& D_{f}^{t o t}=\sum_{l=1}^{L} \sum_{t=1}^{T} D_{f l t} \quad \text { total amount of customer demand for product family } f \text { during the planning } \\
& \text { horizon } T \text {; } \\
& D_{f l t}^{N \text { Null }} \quad 1 \text { if demand for product family } f \text { from the customer } l \text { in } t \text { is not null; } 0 \\
& \text { otherwise. }
\end{aligned}
$$

The meaning of the previously introduced variables (e.g. $z_{k}, k, t$, etc.) and parameters (e.g. $d_{k}^{\prime}, W$, etc.) is that of Section 3. The objective function (2) minimizes the same costs described in the previously discussed model, but by introducing the new index $f$ the contributions of different families of product can be separated. 


\section{Single-commodity, multi-period, 2-stage open/closed model}

In the previous models the generic facility is kept open or closed for the whole length of the planning horizon of time $T$. In this section the SCMP2S model is extended by allowing the status of each facility to change during $T$ : the available facilities can be opened (i.e. reopened) or closed in different periods of time $t$.

The proposed model is:

$$
\begin{aligned}
& \operatorname{Min} \sum_{k=1}^{K}\left(c_{k}^{\prime} d_{k}^{\prime} \sum_{t=1}^{T} x_{k t}^{\prime}\right)+\sum_{k=1}^{K} \sum_{l=1}^{L}\left(c_{k l} d_{k l} \sum_{t=1}^{T}\left(x_{k l t}+x_{k l t}^{\text {delay }}\right)\right)+\sum_{k=1}^{K} \sum_{t=1}^{T} c^{p} x_{k t}^{\prime}+\sum_{k=1}^{K} \sum_{t=1}^{T} c^{s} I_{k t}+ \\
& +\sum_{k=1}^{K} \sum_{t=1}^{T} f_{k t} z_{k t}+\sum_{k=1}^{K} \sum_{t=1}^{T} v_{k} x_{k t}^{\prime}+\sum_{k=1}^{K} \sum_{t=1}^{T}\left(c_{k}^{c l} w_{k t}+c_{k}^{o p} a_{k t}\right)+W \cdot \sum_{k=1}^{K} \sum_{l=1}^{L} \sum_{t=1}^{T} S_{k l t}
\end{aligned}
$$

subject to

constraints $(1.1)-(1.13)$

$$
\begin{array}{ll}
w_{k t} \geq z_{k, t-1}-z_{k t} & \forall k, \forall t>1 \\
w_{k 1}=1-z_{k t} & \forall k \\
a_{k t} \geq z_{k t}-z_{k, t-1} & \forall k, \forall t>1 \\
a_{k 1}=0 & \forall k \\
x_{k l t} \geq 0 & \forall k, l, t \\
x_{k l t}^{\text {delay }} \geq 0 & \forall k, l, t \\
S_{k l t} \geq 0 & \forall k, l, t \\
I_{k t} \geq 0 & \forall k, t \\
z_{k t,} y_{k l t}, w_{k l t}, a_{k l t} \in\{0,1\} & \forall k, l, t
\end{array}
$$

The new introduced decision variables are:

$$
\begin{array}{ll}
z_{k t} & 1 \text { if the RDC } k \text { belongs to the distribution network in } t ; 0 \text { otherwise; } \\
w_{k t} & 1 \text { if the RDC } k \text { is closed in } t ; 0 \text { otherwise; } \\
a_{k t} & 1 \text { if the RDC } k \text { is opened in } t ; 0 \text { otherwise. }
\end{array}
$$

The new set of input data is:

$$
\begin{array}{ll}
f_{k t} & \text { fixed operating cost of the RDC } k \text { in } t ; \\
c_{k}^{c l} & \text { cost of opening RDC } k ;
\end{array}
$$


$c_{k}^{o p} \quad$ cost of closing RDC $k$.

A new set of constraints are introduced: (3.1) - (3.9). In particular, the relationship (3.1) identifies whether or not RDC $k$ closes in the period $t$. The binary variable $w_{k t}$ is equal to 1 only if $z_{k, t-1}=1$ and $z_{k t}=0$ (i.e. if RDC $k$ is open in $t-1$ and close in $t$ ); otherwise $w_{k t}$ is equal to 0 .

It is assumed that all available facilities are operating (i.e. open) at the beginning of the planning horizon (constraint 3.4): as a result, constraint (3.2) states that in the first period the RDC $k$ is only closed if it is not selected by the optimal solution of the $\operatorname{LAP}\left(z_{k 1}=0\right)$.

Constraint (3.3) concerns the opening of RDC $k$ in $t$ : the value of $a_{k t}$ is equal to 1 only if $z_{k, t-1}=0$ and $z_{k t}=1$ (opening in $t$ ); in all other situations the variable $a_{k t}$ is equal to 0 .

If it is assumed that all facilities are closed at the beginning of the planning horizon, then constraints (3.2) and (3.4) must change as follows:

$$
\begin{aligned}
& \left(w_{k 1}=1-z_{k t}\right) \rightarrow\left(w_{k 1}=0\right) \\
& \left(a_{k 1}=0\right) \rightarrow\left(a_{k 1}=z_{k 1}\right)
\end{aligned}
$$

\section{Single-commodity, multi-period, 3-stage model}

The previously described SCMP2S model has been extended in order to include another type of nodes: the production plants.

The proposed model is:

$$
\begin{aligned}
& \operatorname{Min} \sum_{i=1}^{I}\left(c_{i}^{\prime \prime} d_{i}^{\prime \prime} \sum_{t=1}^{T} x_{i t}^{\prime \prime}\right)+\sum_{k=1}^{K}\left(c_{k}^{\prime} d_{k}^{\prime} \sum_{t=1}^{T} x_{k t}^{\prime}\right)+\sum_{k=1}^{K} \sum_{l=1}^{L}\left(c_{k l} d_{k l} \sum_{t=1}^{T}\left(x_{k l t}+x_{k l t}^{\text {delay }}\right)\right)+\sum_{i=1}^{I} \sum_{t=1}^{T} c^{p} x_{i t}^{\prime \prime}+\sum_{k=1}^{K} \sum_{t=1}^{T} c^{s} I_{k t}+ \\
& +\sum_{k=1}^{K} \sum_{t=1}^{T} c^{s} I_{k t}+\left(f^{C D C}+\sum_{i=1}^{I} \sum_{t=1}^{T} v^{C D C} x_{i t}^{\prime \prime}\right)+\sum_{k=1}^{K}\left(f_{k} z_{k}+\sum_{t=1}^{T} v_{k} x_{k t}^{\prime}\right)+W \cdot \sum_{k=1}^{K} \sum_{l=1}^{L} \sum_{t=1}^{T} S_{k l t}
\end{aligned}
$$


subject to:

constraints (1.3) - (1.18)

$$
\begin{array}{ll}
x_{i t}^{\prime \prime} \leq C_{i t}^{P} & \forall i, t \\
\sum_{i=1}^{I} x_{i, t-l t^{\prime \text { prod }}}^{\prime \prime}=\sum_{k=1}^{K} x_{k t}^{\prime} & \forall t
\end{array}
$$

The new inputs are:

$$
\begin{aligned}
& i=1, \ldots ., I \\
& c_{i}^{\prime \prime} \\
& d_{i}^{\prime \prime} \\
& f^{C D C} \\
& v^{C D C}
\end{aligned}
$$

production plant;

unit transportation cost from production plant $i$ to the CDC; distance from production plant $i$ to the CDC;

fixed operating cost of the CDC;

variable unit cost based on the quantity flowing through the CDC.

The new decision variable $x_{i t}^{\prime \prime}$ represents the product quantity from production plant $i$ to the CDC in $t$.

Finally, a more general problem in which there are different CDCs was examined.

In this case the new objective function is:

$$
\begin{aligned}
& \operatorname{Min} \sum_{i=1}^{I} \sum_{j=1}^{J}\left(c_{i j}^{\prime \prime} d_{i j}^{\prime \prime} \sum_{t=1}^{T} x_{i j t}^{\prime \prime}\right)+\sum_{j=1}^{J} \sum_{k=1}^{K}\left(c_{j k}^{\prime} d_{j k}^{\prime} \sum_{t=1}^{T} x_{j k t}^{\prime}\right)+\sum_{k=1}^{K} \sum_{l=1}^{L}\left(c_{k l} d_{k l} \sum_{t=1}^{T}\left(x_{k l t}+x_{k l t}^{r i t}\right)\right)+\sum_{i=1}^{I} \sum_{j=1}^{J} \sum_{t=1}^{T} c^{p} x_{i j t}^{\prime \prime}+ \\
& +\sum_{k=1}^{K} \sum_{t=1}^{T} c^{s} I_{k t}+\sum_{j=1}^{J}\left(f_{j} \alpha_{j}+\sum_{i=1}^{I} \sum_{t=1}^{T} v_{j} x_{i j t}^{\prime \prime}\right)+\sum_{k=1}^{K}\left(f_{k} z_{k}+\sum_{t=1}^{T} v_{k} x_{k t}^{\prime}\right)+W \cdot \sum_{k=1}^{K} \sum_{l=1}^{L} \sum_{t=1}^{T} S_{k l t}
\end{aligned}
$$

where:

$$
\begin{array}{ll}
i=1, \ldots, I & \text { production plant; } \\
j=1, \ldots, J & \text { central distribution center (CDC); } \\
c_{i j}^{\prime \prime} & \text { unit cost of transportation from the production plant } i \text { to the CDC } j ; \\
d_{i j}^{\prime \prime} & \text { distance from production plant } i \text { to the CDC } j ; \\
c_{j k}^{\prime} & \text { unit cost of transportation from the CDC } j \text { to the RDC } k ; \\
d_{j k}^{\prime} & \text { distance from the CDC } j \text { to the RDC } k ; \\
f_{j} & \text { fixed operating cost of the CDC } j ; \\
x_{i j t}^{\prime \prime} & \text { product quantity from production plant } i \text { to the } \mathrm{CDC} j \text { in } t ;
\end{array}
$$


$\begin{array}{ll}x_{j k t}^{\prime} & \text { product quantity from the } \mathrm{CDC} j \text { to the } \mathrm{RDC} k \text { in } t \\ \alpha_{j} & 1 \text { if the CDC } j \text { belongs to the distribution network; } 0 \text { otherwise. }\end{array}$

The following new addends have been introduced into the objective function:

- global cost for the distribution of products from the first level to the CDCs level;

- costs (fixed and variable) associated with managing the pool of CDCs.

\section{$7 \quad$ Case study}

The models described above were used to rationalize and optimize a logistic network distributing components from a leading electronics company. The Actual configuration (i.e. AS IS) of the distribution network is based on the existence of four different levels (Figure 2):

1. Production plants;

2. 1 CDC located in Italy;

3. 5 RDCs located in the UK, France (FR), Germany (D), Taiwan (TW), and the USA;

4. more than 1100 customers.

[Insert Figure 2 about here]

Application of the proposed two-stage model was justified because more than $90 \%$ of the delivered products actually flow through the CDC (less than $10 \%$ of the products are shipped directly from the production plants to customers). Therefore, only the section of the logistic network below the CDC is considered, with the production level being omitted (Figure 2).

As the company supplies a large number of customers, the customers were aggregated by calculating a barycentric point of demand for each geographical area in order to simplify the 
particular instance and to quantify the distance between two generic nodes. The procedure adopted to find the barycentric locations of demand is based on the following steps:

- Determination of the longitude and latitude for each customer in each geographic area.

- Determination of the Cartesian coordinates of each customer using the Mercator Projection, whose equations are:

$x=a \cdot \lambda$

$y=a \cdot \ln \left[\left(\frac{1-e \sin \varphi}{1+e \sin \varphi}\right)^{e / 2} \operatorname{tg}\left(\frac{\pi}{4}+\frac{\varphi}{2}\right)\right]$

where:

$\lambda \quad$ longitude (radians);

$\varphi \quad$ latitude (radians);

a semi-major axis of the Earth (about $6.378 \mathrm{Km}$ );

$e \quad$ eccentricity of the Earth (about 0,08182);

$x, y \quad$ Cartesian coordinates.

- Determination of the barycentric point of demand for each geographic area $g$ :

$$
\begin{array}{r}
x_{B}^{g}=\frac{\sum_{i \in g} x_{i} w_{i}}{\sum_{i \in g} w_{i}} \\
y_{B}^{g}=\frac{\sum_{i \in g} y_{i} w_{i}}{\sum_{i \in g} y_{i}}
\end{array}
$$

where:

$g \quad$ geographic area;

$w_{i} \quad$ product quantity delivered to the customer $i$ that belongs to the geographic area $g$. 
Application of the proposed procedure identified about 50 barycentric points of demand. Each one represents a cluster of customers tolerating different delivery lead times. Thus, the generic barycentric point of demand has been segmented according to the pre-defined response time $\left(T_{l}\right)$ of each customer. As a result, the total number of modeled virtual points of demand is 254 .

Products number several thousand, but the product mix could be reduced to a single product because the amount for each type of product is so small that individual quantities are unimportant: the flow of products through the system is measured in kilograms or tons.

To allow direct shipments from the CDC to the end customer, the so-called "virtual DC" has been introduced: products that flow through this DC are shipped directly from Italy to the demand points located throughout the world.

After accurate simplification of the distribution network, the SCMP2S model was applied to the rationalization of the aforementioned supply chain using a linear programming solver and assuming a one-year time horizon (i.e. $T$ equals one year). In particular, the data available for the distribution activities of the company in this case study refer to the year 2004. The unit time-period $t$ within the planning horizon is assumed to be 2-weeks.

The first step was to quantify the optimal product flows along the "Actual" supply chain and the annual logistic and production costs by applying the model introduced in Section 3 to the AS-IS configuration. Thus, in this first simulation, by assigning the value 1 to $z_{k}$ for each DC, all of the available RDCs are forced to stay open. Figure 3 illustrates the locations of the distribution centers in the Actual network.

[Insert Figure 3 about here] 
[Insert Figure 4 about here]

The solution to the problem is generated by applying the MPL Modeling System (Maximal Software, Inc.) using a personal computer (Pentium IV $3.2 \mathrm{GHz}$ ), which took a CPU time of about 2 hours and 5 minutes. The number of variables is about 183276 (of which 42678 are binary), and the number of constraints is 331680 .

Figure 5 illustrates the product flows between the different levels in the logistic network in an example unit time period $t$.

[Insert Figure 5 about here]

The SCMP2S model results revealed that three of the five Actual RDCs can be kept closed: D, TR, and the one in the UK. During the unit time period $t$, approximately 195 tons of products are shipped directly from the CDC to the end customer, and the company has a storage quantity of 23 tons to manage in the DC located in Italy at the end of time period $t$. During $t$, about 9 tons of product are transported to the RDC located in Taiwan and delivered directly to the customers in the same period of time. In the case of the RDC located in the USA, about 12 tons are delivered to customers in $t$ and a stock of approximately 4 tons is built up by the end of the analyzed time period. Similar conclusions can be drawn for each period of time $t$ belonging to the horizon $T$, which can effectively support the management of logistic material flows. 
Figure 6 shows the optimal production level and the available production capacity in each time period $t$ during the planning horizon $T$ : the system capacity is saturated in several unit time periods $t$

[Insert Figure 6 about here]

Figure 7 illustrates the trend in storage quantities for the DCs kept open (ITA, the USA, and TW) during the planning time $T$.

[Insert Figure 7 about here]

Table 1 presents the annual logistic reduction costs, expressed in percentages, passing from the ASIS configuration to the optimal one (called "Best" configuration).

[Insert Table 1 about here]

As expected, the global transportation cost from the CDC to the RDCs is lower in the Best configuration (the number of open RDCs is smaller than the Actual configuration). On the other hand, the global transportation cost from the RDCs to the points of demand increases (in the Actual configuration all five available RDCs are kept open to serve less distant markets).

The cost associated with managing the set of RDCs is reduced by $69 \%$. In fact, the Best configuration closes three RDCs out of the five "Actual" DCs. The annual production cost is unchanged because the overall demand is the same in both configurations. The annual inventory holding cost is slightly increased in the Best configuration. On the whole, cost savings of more than $€ 900000$ could be achieved by adopting the Best configuration. 
In order to evaluate the effectiveness and robustness of the optimal solution, a sensitivity analysis was performed in order to quantify how the outcome of the model varies when demand is higher or lower than expected. Further simulations considered $3 \%$ and $5 \%$ increments/decrements in demand during the generic time period $t$ : all the solutions obtained indicate that the optimal configuration of the logistic network is always composed of the 3 warehouses (the CDC in Italy, and two RDCs in Taiwan and the USA). Similar trends in inventory level were found in all the simulated scenarios. An interesting solution was obtained by applying the proposed SCMP2S model to new potential locations (site generating problem): the set of candidate facility sites was extended to some of the more significant barycentric points of demand. The optimal solution is made of DCs located in Italy, Taiwan, the USA, and also Turkey (as illustrated in Figure 8).

[Insert Figure 8 about here]

A much more accurate rationalization of the logistic network requires a multi-commodity approach. In particular, the company production was differentiated into two different product families (Direct Current - DC, and Alternating Current - AC products) and the MCMP2S model was applied. The solution specifies the optimal material flows throughout the supply chain for both families. By discriminating between the AC and the DC families in an example unit time period $t$, Figure 9 is able to show the inventory levels and the product flows between the different logistic nodes in the distribution network.

[Insert Figure 9 about here]

Figure 10 illustrates the optimal production levels for both the AC and the DC family during the planning horizon $T$. 
[Insert Figure 10 about here]

Finally, the solution found by applying the open/closed model also suggests the RDC in Germany should only be open for the four central months of the year.

\section{Conclusions and further research}

This study presents and discusses the application of a set of innovative models for the single commodity and multi-commodity dynamic (i.e. multi-period) location allocation problem (LAP). The proposed models are able to support the best management of weekly and daily product fulfillment in long and large scale supply chain operating worldwide. As a result, they are capable of replacing any multi-facility Material Requirement Planning instruments and techniques because they are cost based models, and by generating the optimal solution, they minimize the global logistic cost.

The effectiveness of these mixed integer linear models is demonstrated by the ability of a standard programming solver to identify the optimal solution and support management in designing and controlling the distribution network, which minimizes the management costs by controlling delay times, as well as the production and storage capacities of the plant and warehousing facilities, and customer service levels.

As a result, in contrast to several FL studies in the literature based on different problem modeling, the proposed models do not need to design ad-hoc solving algorithms. The models presented in this paper easily and rapidly identify the optimal location of logistic facilities in a worldwide distribution network and the allocation of customer demand to them, and also support some important tactical decisions. 


\begin{abstract}
The case study presented in this paper is composed of more than 330000 constraints and 180000 variables, and demonstrates the efficacy and the efficiency of the proposed SCMP2S and MCMP2S models. Compared to the so-called Actual configuration (AS-IS) of the network, the best solution of the problem guarantees a cost reduction of approximately $€ 900000 /$ year.

Lastly, further research needs to concentrate on introducing additional new constraints. A few examples:
\end{abstract}

- safety stock optimization capable of measuring, controlling, and optimizing the customer service levels;

- stochastic demand;

- economies of scale in terms of transportation and production;

- inventory pooling;

- reverse logistics (e.g. product recovery activities for the purposes of recycling, remanufacturing, reuse, etc.);

- decisions regarding requirements for components, subassemblies, and raw materials as commonly described by the bill-of-materials.

\title{
Acknowledgements
}

The authors thank the anonymous referees for their constructive input and comments, which served to improve the manuscript.

\section{References}

Ambrosino, D. and Scutellà, M.G., Distribution network design: new problems and related models. European Journal of Operational Research, 2005, 165, 610-624. 
Amiri, A., Designing a distribution network in a supply chain system: formulation and efficient solution procedure. European Journal of Operational Research, 2006, 171, 567-576.

Badri, M.A., Combining the analytic hierarchy process and goal programming for global facility location-allocation problem. International Journal of Production Economics, 1999, 62, 237-248.

Byunghak, L. and Cheol-Han, K., A methodology for designing multi-echelon logistics networks using mathematical approach. International Journal of Industrial Engineering:Theory Applications and Practice, 2003, 10, 360-366.

Blackhurst, J., Wu, T. and O'Grady, P., Network-based approach to modelling uncertainty in a supply chain. International Journal of Production Research, 2004, 42, 1639-1658.

Canel, C., Khumawala, B.M., Law, J. and Loh, A., An algorithm for the capacitated, multicommodity multi-period facility location problem. Computers \& Operations Research, 2001, 28, 411-427.

Catena, M., Manzini, R., Pareschi, A., Persona, A. and Regattieri, A., Integrated approach for plant layout design in supply chain, in 17th International Conference on Production Research (ICPR-17), 2003, Blacksburg Virginia (USA).

Chakravarty, A.K., Profit margin, process improvement and capacity decisions in global manufacturing. International Journal of Production Research, 1999, 37, 4235-4257.

Chen, I.J. and Paularaj, A., Understanding supply chain management: critical research and a theoretical framework. International Journal of Production Research, 2004, 42(1), 131-163.

Chiyoshi, F.Y., Galvão, R.D. and Morabito, R., A note on solutions to the maximal expected covering location problem. Computers \& Operations Research, 2002, 30, 87-96.

Chopra, S., Meindl, P., Supply Chain Management: Strategy, Planning and Operation, 2003 (Prentice Hall: New Jersey).

Current, J., Ratick, S. and ReVelle, C., Dynamic facility location when the total number of facilities is uncertain: A decision analysis approach. European Journal of Operational Research, 1997, 110, 597-609.

Daskin, M.S., Facility location in supply chain design. Working Paper No. 03-010, Department of Industrial Engineering and Management Science, Northwestern University, Evaston, Illinois, 2003.

Ferrari, E., Pareschi, A., Persona, A. and Regattieri, A., Plant layout computerized design: Logistic and Re-layout Program (LRP). International Journal of Advanced Manufacturing Technology, 2003, 21(12), 917-922.

Francis, R.L., McGinnis, L.F. and White, J.A., Locational Analysis. European Journal of Operational Research, 1983, 12(3), 220-252. 
Francis, R.L., McGinnis, L.F., White, J.A., Facility Layout and Location, 1992 (Prentice Hall: New Jersey).

Gen, M. and Syarif, A., Hybrid genetic algorithm for multi-time period production/distribution planning. Computers \& Industrial Engineering, 2005, 48, 799-809.

Ghiani, G., Grandinetti, L., Guerriero, F. and Musmanno, R., A lagrangean heuristic for the plant location problem with multiple facilities in the same site. Optimization Methods and Software, 2002, 17(6), 1059-1076.

Jacobsen, S.K., Multiperiod capacitated location models. In Discrete Location Theory, edited by P.D. Mirchandani and R.L. Francis, pp.173-208, 1990 (John Wiley \& Sons, Inc.: New York)

Jalisi, Q.W.Z. and Cheddad, H., Third party transportation: A case study. International Journal of Industrial Engineering: Theory Applications and Practice, 2000, 7(4), 348-351.

Kilkenny, M. and Thisse, J.F., Economics of location: A selective survey. Computers \& Operations Research, 1999, 26, 1369-1394.

Klose, A. and Drexl, A., Facility location models for distribution system design. European Journal of Operational Research, 2005, 162, 4-29.

Lawrence, V.S. and Daskin, M.S., Reliability models for facility location: the expected failure cost case. Transportation Science, 2005, 39, 400-416.

Levin, Y. and Ben-Israel, A., A heuristic method for large-scale multi-facility location problems. Computers \& Operations Research, 2004, 31, 257-272.

Lin, C-W.R. and Chen, H-Y.S., Dynamic allocation of uncertain supply for the perishable commodity supply chain. International Journal of Production Research, 2003, 41, 3119-3138.

Lodree, E., Jang, W. and Klein, C.M., Minimizing response time in a two-stage supply chain system with variable lead time and stochastic demand. International Journal of Production Research, 2004, 42, 2263-2278.

Love, R.F., Morris, J.G. and Wesolowsky, G.O., Facilities Location. Models \& Methods, 1988 (North-Holland: New York).

Manzini, R., Ferrari, E., Gamberi, M., Gamberini, R., Pareschi, A. and Regattieri, A., Evaluation and comparison of different fulfillment policies for inventory/distribution multi-echelon systems, in 11th IFAC Symposium on information control problems in manufacturing, 2004, Salvador, Brazil.

Manzini, R., Ferrari, E., Regattieri, A. and Persona A., An expert system for the design of a multiechelon inventory/distribution fulfillment system, in Proceedings of the 18th International Conference on Production Research (ICPR-18), 2005, Fisciano - SA (Italy). 
Manzini, R., Gamberi, M. and Regattieri, A., Applying mixed integer programming to the design of a distribution logistic network. International Journal of Industrial Engineering: Theory Applications and Practice, 2006, 13(2), 207-218.

Melkote, S. and Daskin, M.S., Capacitated facility location/network design problems. European Journal of Operational Research, 2001, 129, 481-495.

Miranda, P.A. and Garrido, R.A., Incorporating inventory control decisions into a strategic distribution network design model with stochastic demand. Transportation Research Part E: Logistics and Transportation Review, 2004, 40, 183-207.

Owen, S.H. and Daskin, M.S., Strategic facility location: a review. European Journal of Operational Research, 1998, 111, 423-447.

ReVelle, C.S., Review, extension and prediction in emergency service siting models. European Journal of Operational Research, 1989, 40, 58-64.

Shen, Z-J.M., Coullard, C. and Daskin, M.S., A joint location-inventory model. Transportation Science, 2003, 37, 40-55.

Shen, Z-J. M., A multi-commodity supply chain design problem. IIE Transactions, 2005, 37, 753762.

Shen, Z-J.M. and Daskin, M.S., Trade-offs between customer service and cost in integrated supply chain design. Manufacturing \& Service Operations Management, 2005, 7, 188-207.

Sule, D. R., Logistics of Facility Location and Allocation, 2001 (Marcel Dekker Inc.: New York).

Sweeney, D.J. and Tatham, R.L., An improved long-run model for multiple warehouse location. Management Science, 1976, 22, 748-758.

Van Roy, T.J. and Erlenkotter, D., A dual-based procedure for dynamic facility location. Management Science, 1982, 28, 1091-1105.

Wesolowsky, G.O., Dynamic facility location. Management Science, 1973, 19, 1241-1248.

Wesolowsky, G.O. and Truscott, W.G, The multiperiod location-allocation problem with relocation of facilities. Management Science, 1975, 22, 57-65.

Young, K.K. and Hwan, K.K., Locating a single facility considering uncertain transportation time. International Journal of Industrial Engineering:Theory Applications and Practice, 2003, 10(4), 467-473. 
Yurimoto, S. and Katayama, N., A model for the optimal number and locations of public distribution centers and its application to the Tokyo metropolitan area. International Journal of Industrial Engineering:Theory Applications and Practice, 2002, 9(4), 363-371.

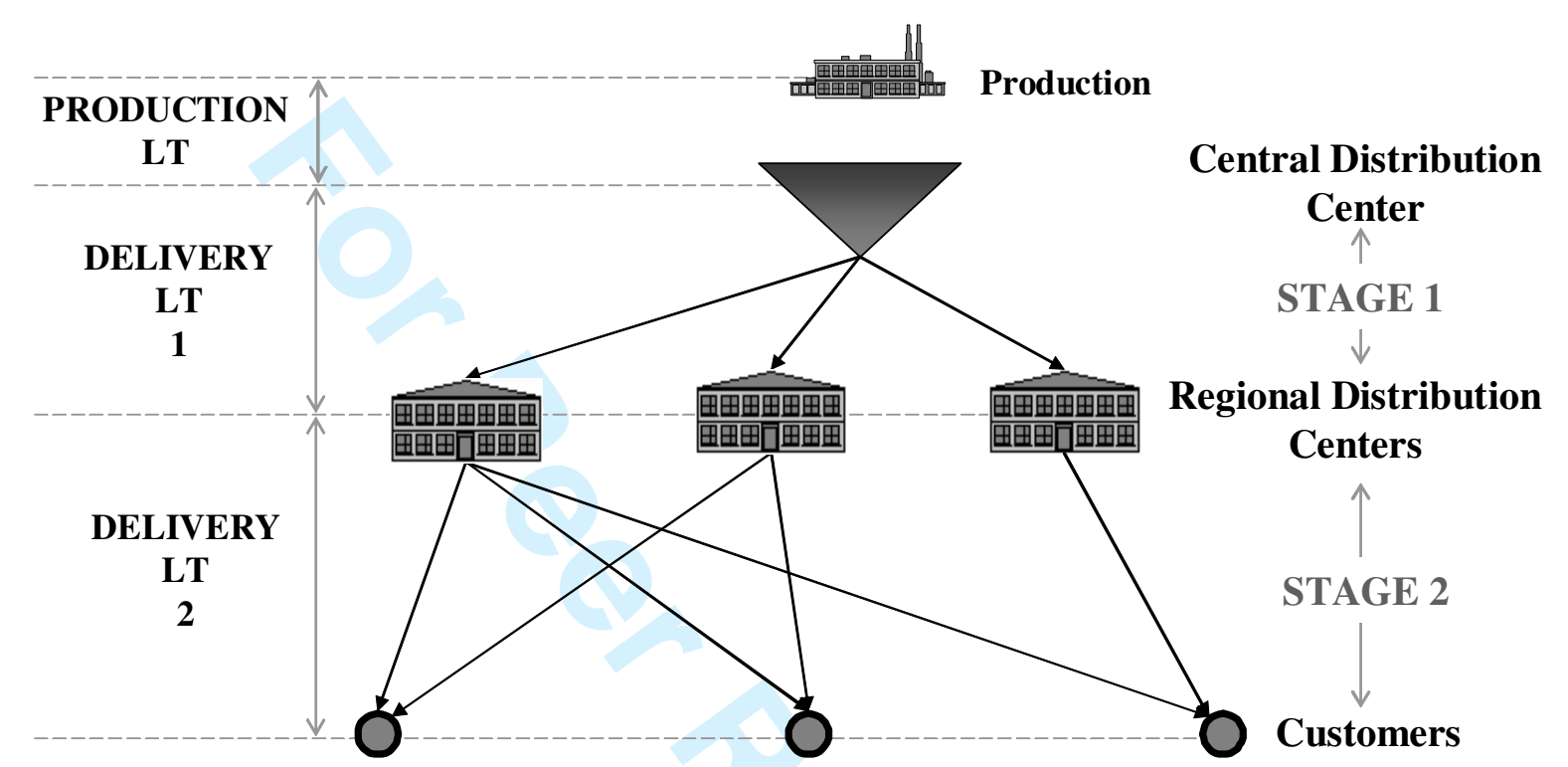

Figure 1. 2-stage logistic network 


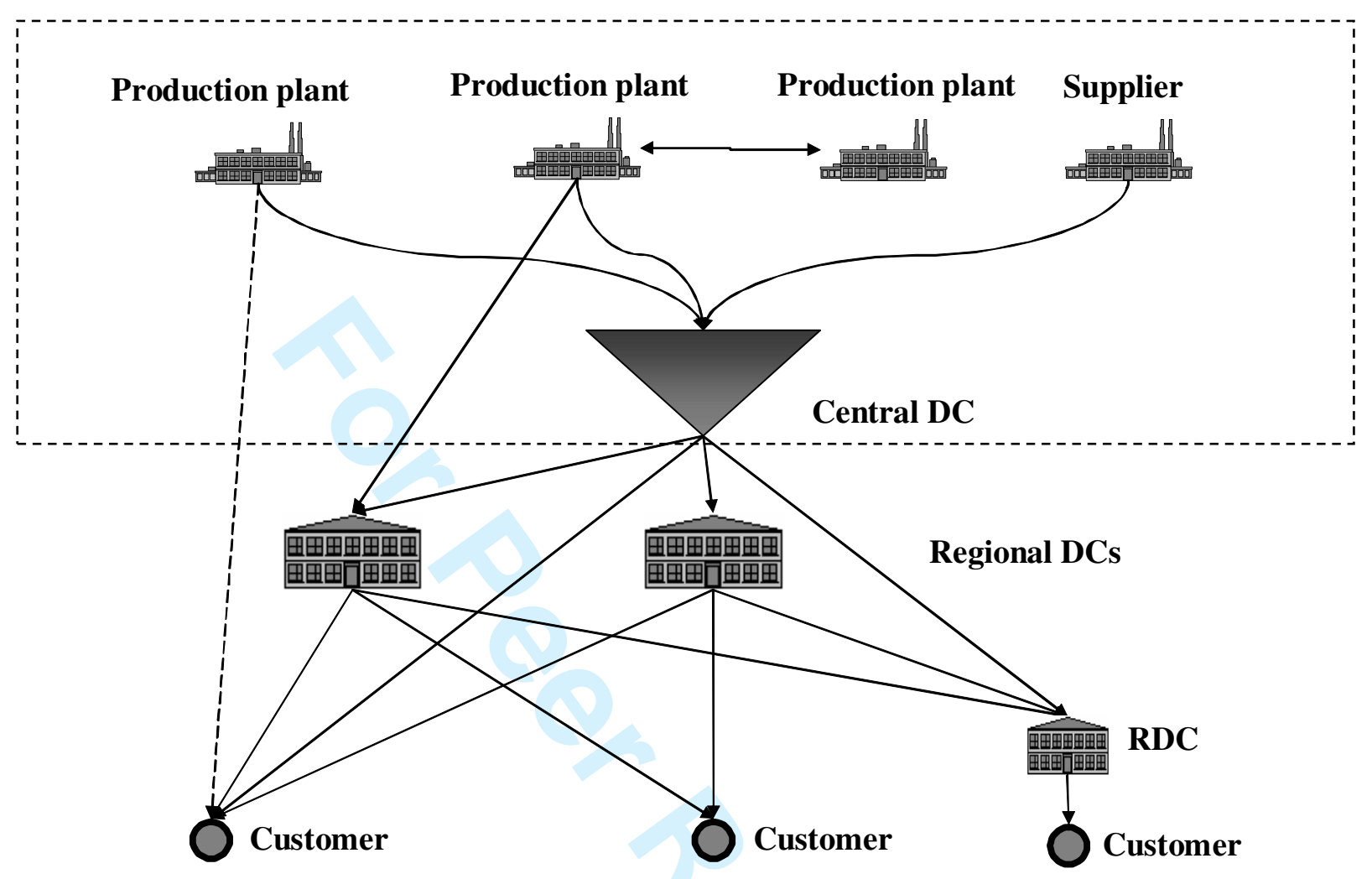

Figure 2. Case study: Distribution network 


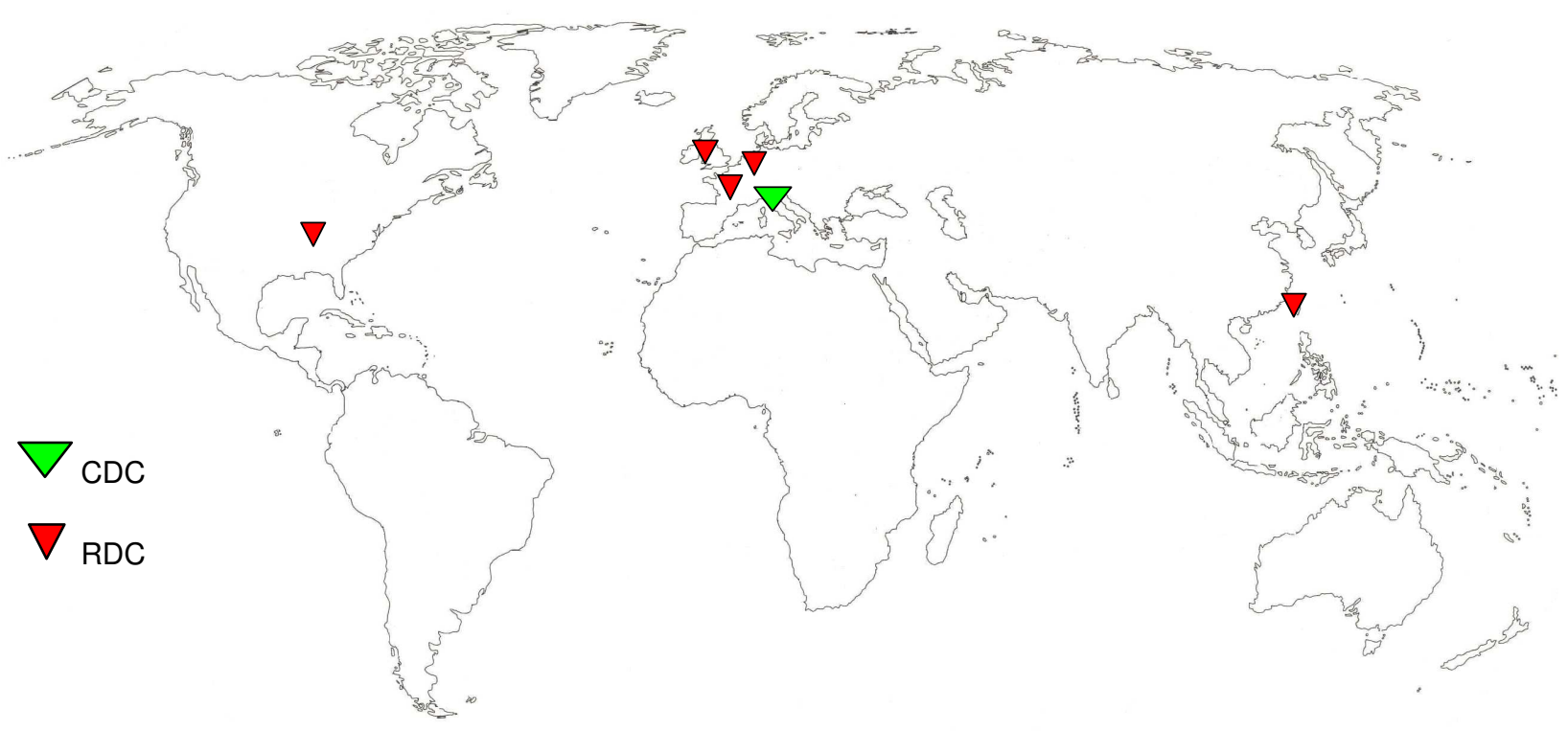

Figure 3. SCMP2S, AS-IS: Actual configuration of the logistic network 


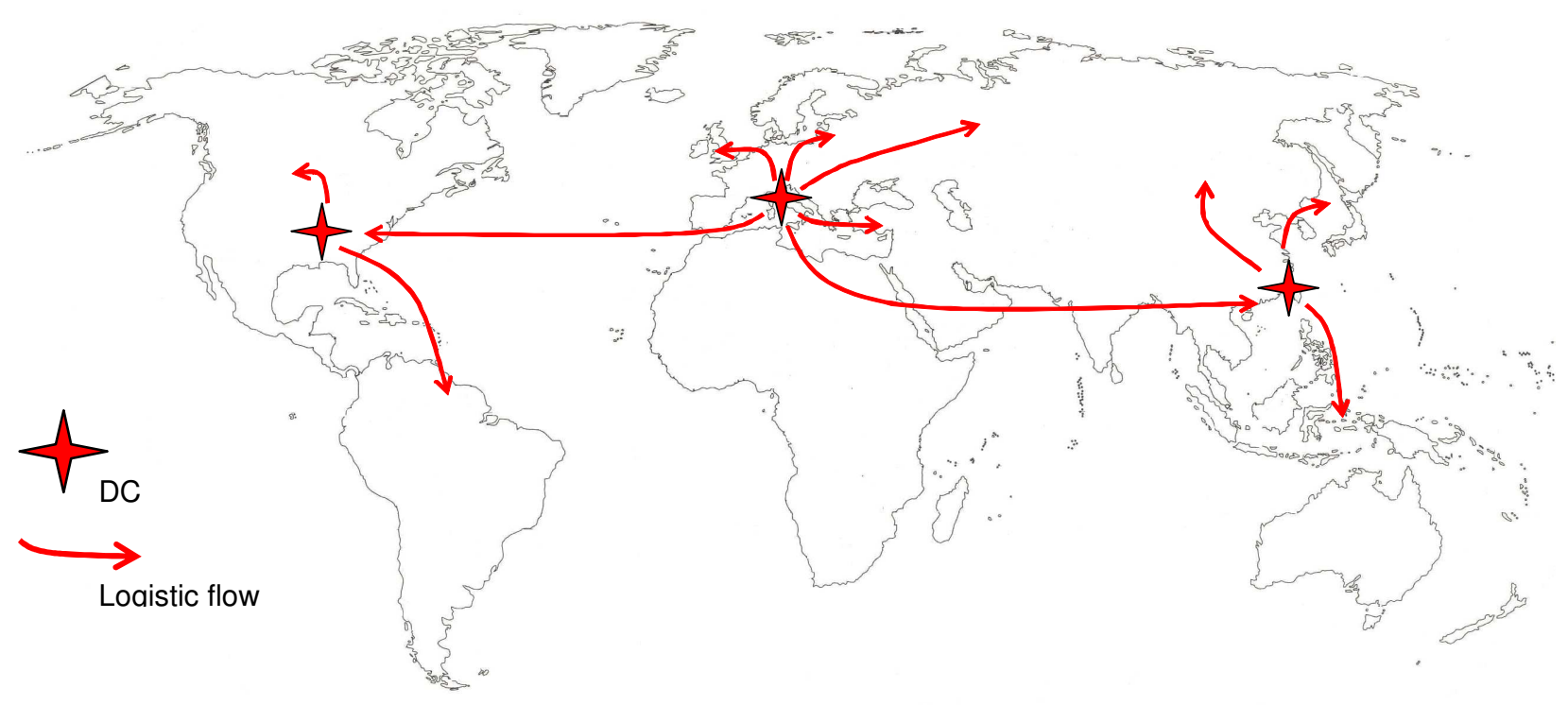

Figure 4. SCMP2S, TO-BE: Optimal configuration of the logistic network 


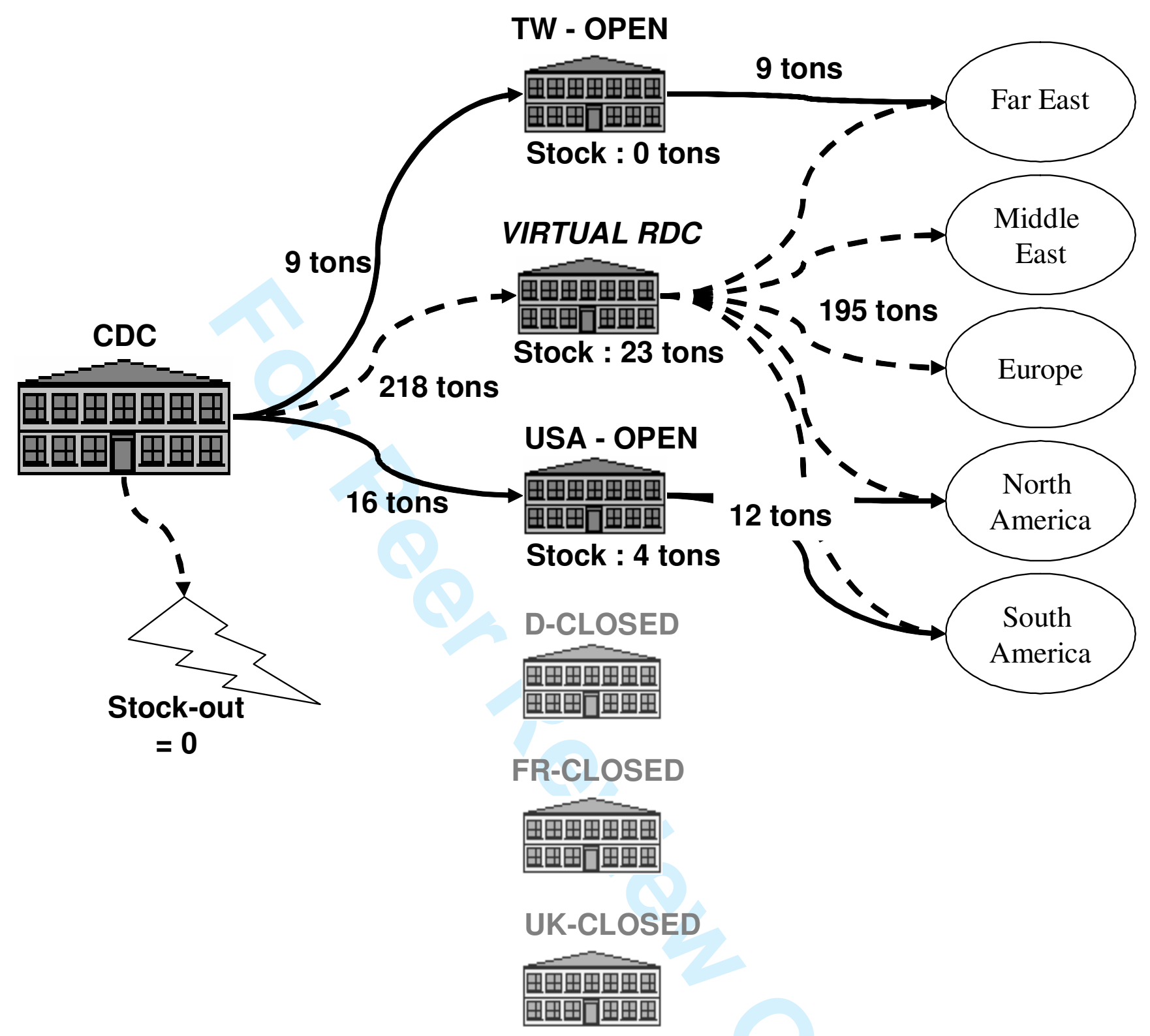

Figure 5. SCMP2S: Example of optimal product flows in a unit time period $t$ 


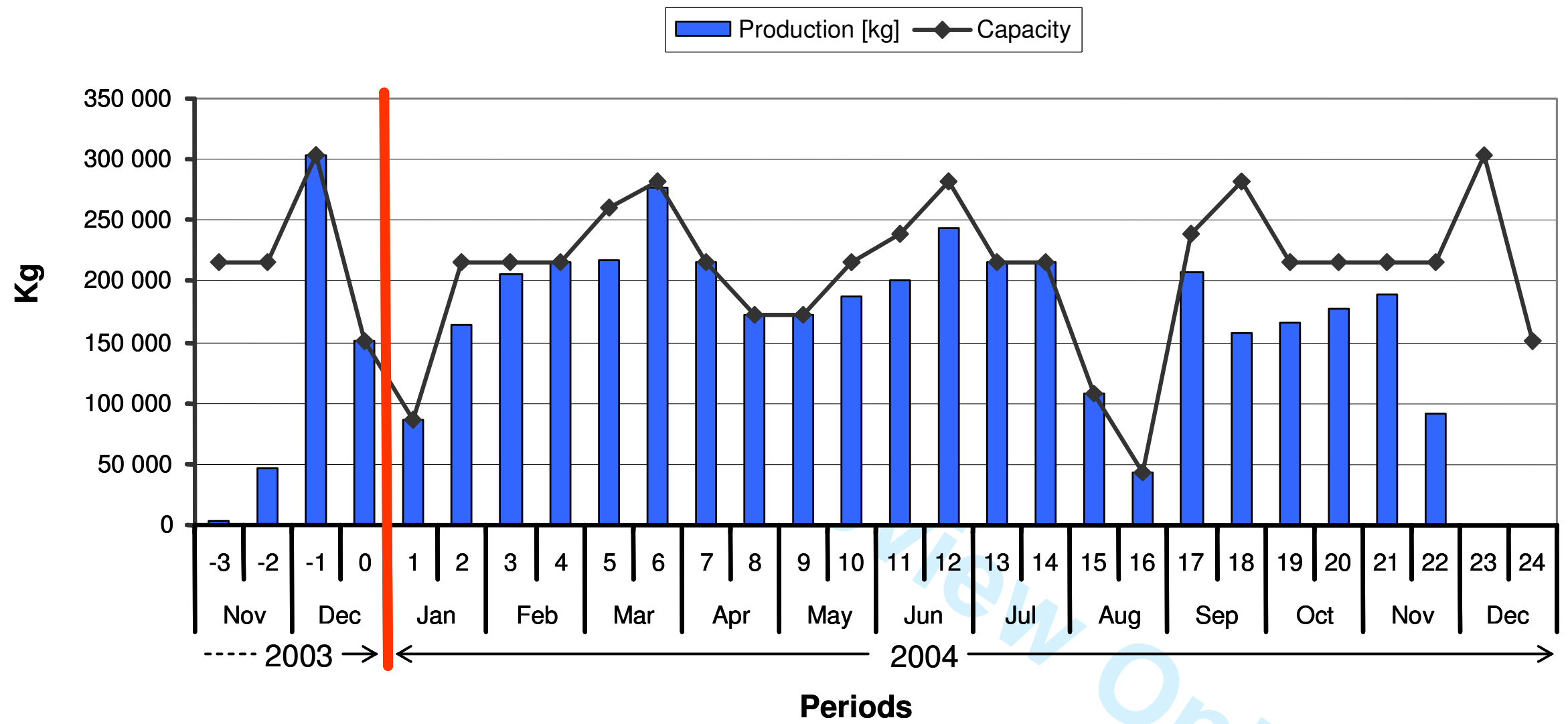

Figure 6. SCMP2S: Optimal production level vs production capacity in $T$ 


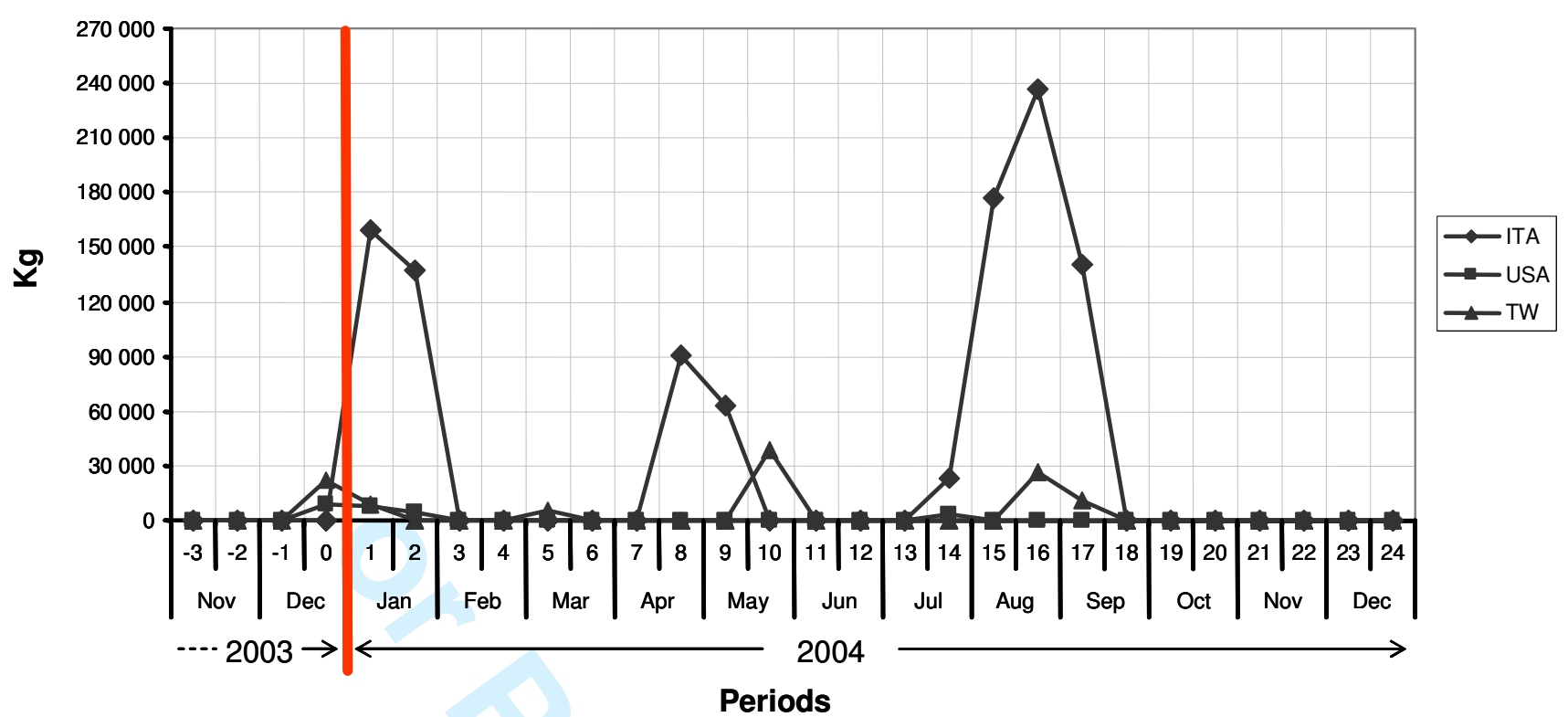

Figure 7. SCMP2S: Storage quantities in ITA, the USA, and TW during $T$ 


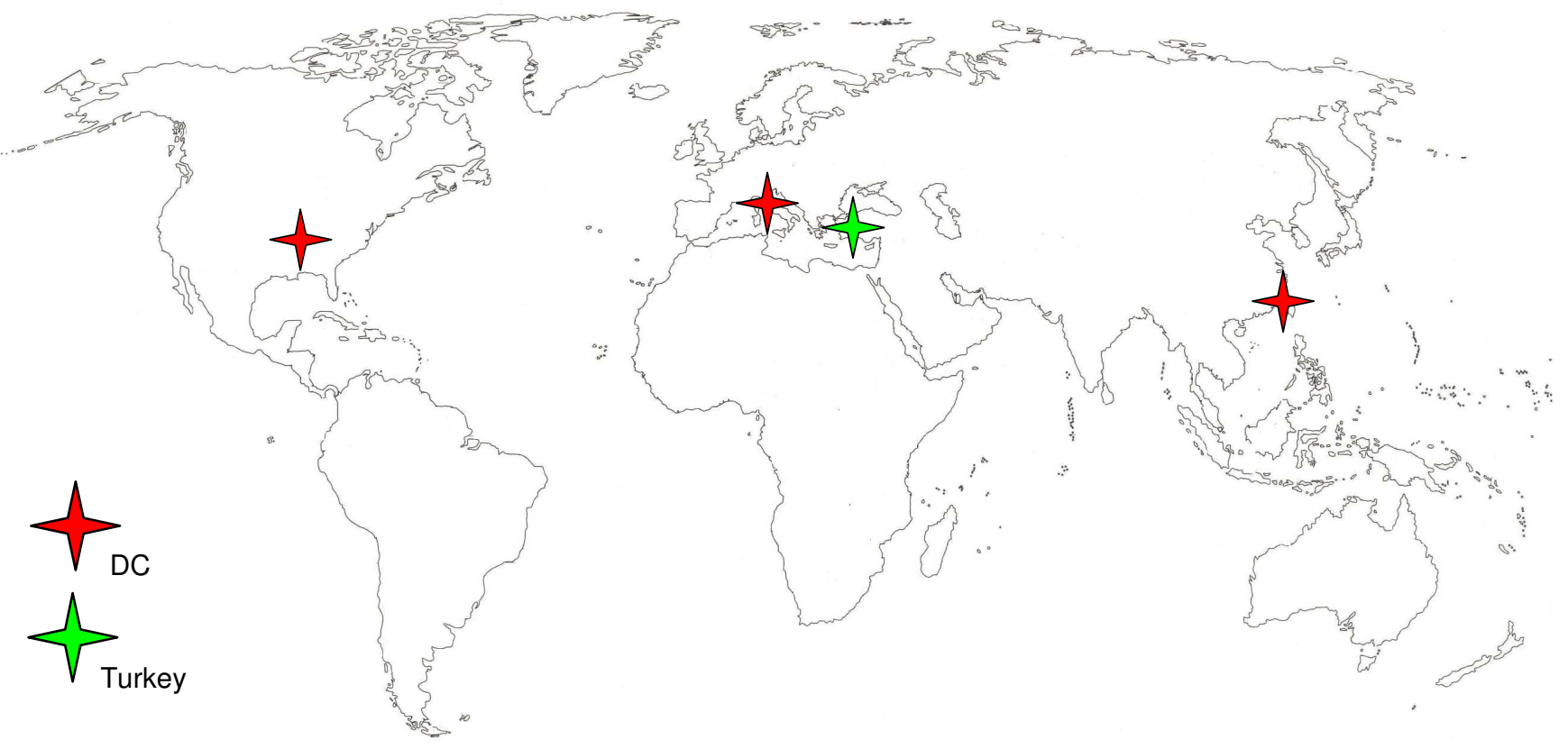

Figure 8. SCMP2S: Site generating problem. 


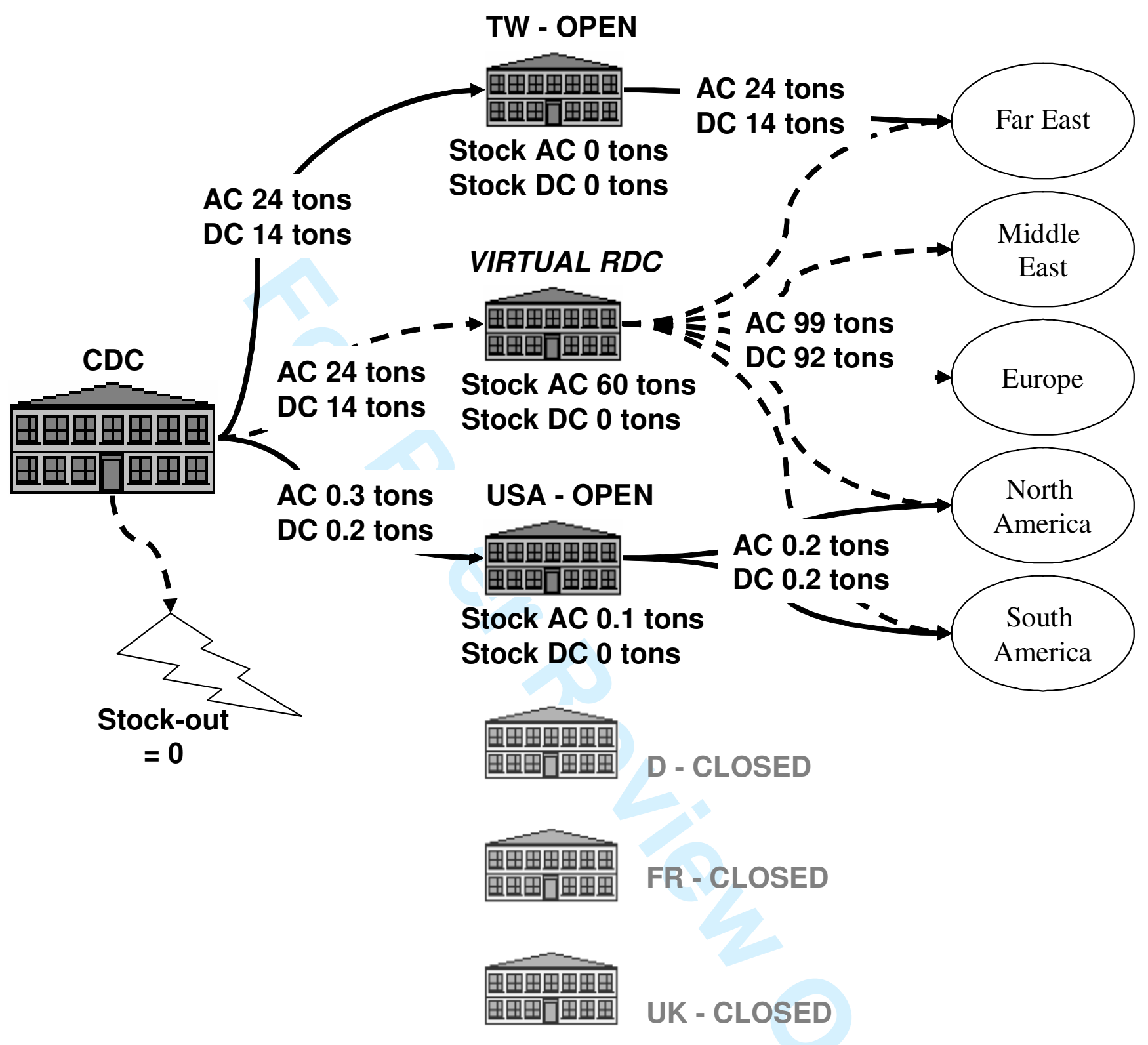

Figure 9. MCMP2S: Optimal product flows in an example unit time period $t$ 


\begin{tabular}{l|c}
\hline Costs of logistics & $\Delta \%$ \\
\hline Transportation cost (CDC-RDCs) & $-47 \%$ \\
Transportation cost (RDCs-points of demand) & $+43 \%$ \\
Total transportation cost & $-5 \%$ \\
Cost of RDCs & $-69 \%$ \\
Cost of CDC & - \\
Total cost of warehouses & $-44 \%$ \\
Inventory holding cost & $+1 \%$ \\
\hline Total cost of logistics & $-\mathbf{1 7 \%}$ \\
\hline
\end{tabular}

Table 1. SCMP2S: AS-IS vs Best configuration. Reduction in annual logistic costs 


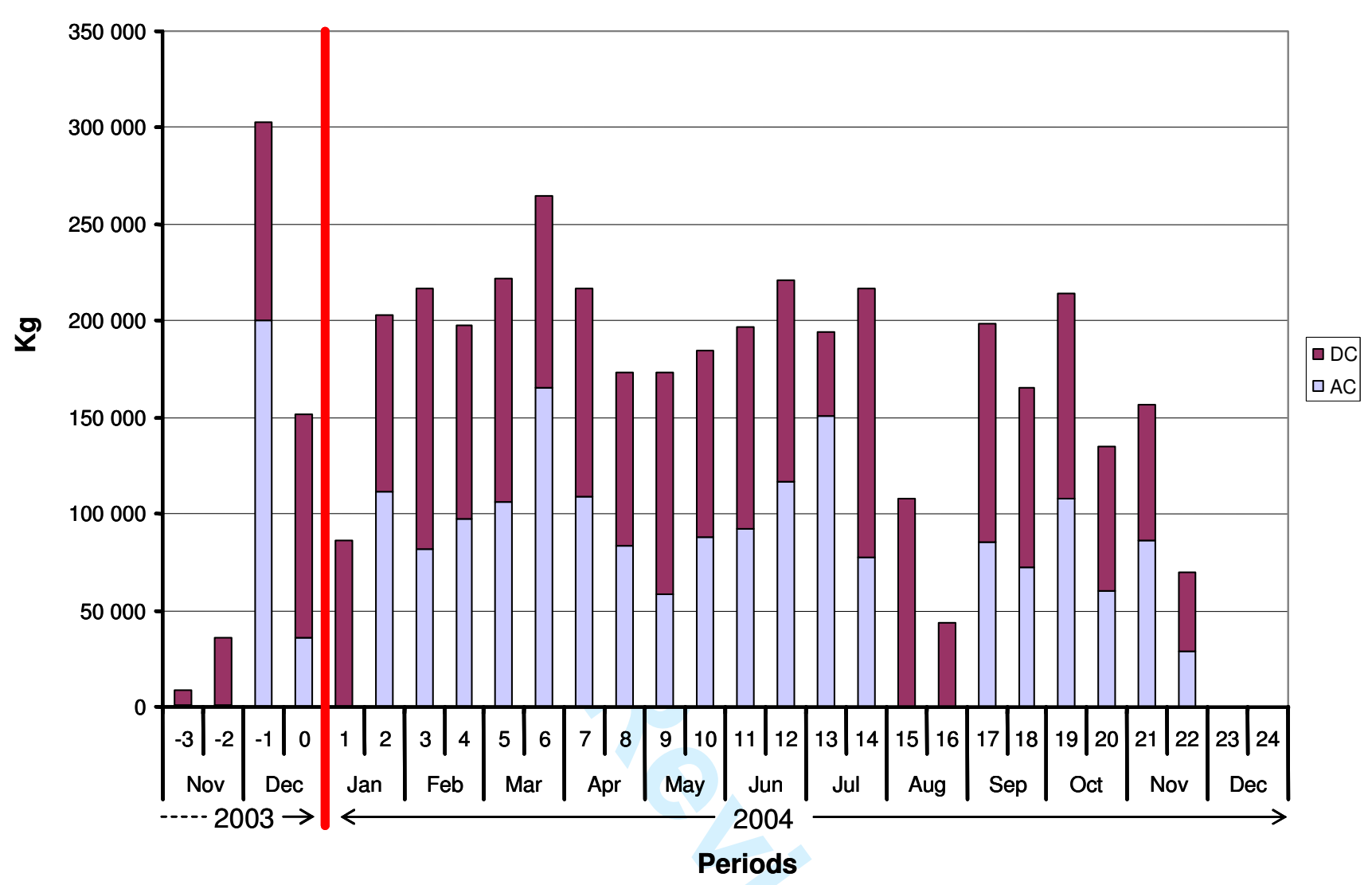

Figure 10. MCMP2S: Production levels for AC and DC product families 